\title{
The effect of aerobic exercise training on gene expression of beta3-adrenergic receptor and beta-arrestin2 in inguinal white adipose tissue of mice fed with a high fat diet
}

\author{
Saeed Daneshyar ${ }^{1 *}{ }^{\circledR}$, Mehdi Bahmani $^{2}{ }^{\circledR}$, Yazdan Fourotan $^{3}{ }^{\circledR}$ \\ ${ }^{1}$ Assistant Professor, Department of Physical Education, Faculty of Humanities, University of Ayatollah Alozma Boroujerdi, \\ Lorestan, Iran \\ ${ }^{2}$ Ph.D., Department of Biochemistry, Faculty of Medicine, Hamedan University of Medical Sciences, Hamedan, Iran \\ ${ }^{3}$ Master of Science, Department of Physical Education and Sport Sciences, Islamic Azad University of Hamedan, Hamedan, \\ Iran
}

*Corresponding Author: Saeed Daneshyar, Department of Physical Education, Faculty of Humanities, University of Ayatollah Alozma Boroujerdi, Boroujerd, Lorestan, Iran. Tel: +989037324793, Fax: 066432102, Email: s.daneshyar@abru.ac.ir

\begin{abstract}
Background and aims: Beta-adrenergic signaling deficiency has been established to be related to obesity and related diseases. Beta3adrenergic receptor (Adrb3) and beta-arrestin2 (Barr2) are pivotal agents in the beta-adrenergic-signaling pathway. This study aimed to investigate the preventive effect of aerobic training on dysregulation of Adrb3 and Barr2 gene expression that was induced by high-fat diet (HFD) in inguinal white adipose tissue of mice.

Materials and Methods: Twenty-one C57BL/6 mice were assigned to three groups as follows: 1) control group ( $\mathrm{n}=7)$, 2) high-fat dietinduced overweight (HFD-OW) $(n=7)$, and 3 ) high-fat diet with aerobic training (HFD-AT) $(n=7)$. The HFD-OW group were fed with a HFD for 12 weeks. The HFD-AT group had aerobic training for six weeks on a treadmill in addition to feeding with the HFD. The real-time polymerase chain reaction (PCR) method was used to measure the gene expression of Adrb3 and Barr2 in inguinal white adipose tissue. Results: The gene expression of Adrb3 did not significantly change between groups $(P>0.05)$. However, the expression of Barr2 in HFDOW group was significantly increased as compared to the control group (1.5-fold: $P=0.001)$. Interestingly, the Barr2 expression in HFD-AT group was significantly lower compared with HFD-OW group $(P=0.045)$.

Conclusion: The results indicated that aerobic training could inhibit the upregulation of Barr2 induced by HFD. It seems that a portion of the preventive effect of aerobic training on the development of obesity may be mediated by inhibiting the Barr2 expression in adipose tissue.

Keywords: Obesity, High-fat diet, $\beta$-Arrestin, Exercise training, White adipose tissue
\end{abstract}

Received: 18 January 2021, Accepted: 1 May 2021, ePublished: 29 September 2021

\section{Introduction}

The worldwide prevalence of overweight and obesity remarkably has increased over the current century to an extent that one-third of the world population is currently classified as obese/overweight (1). Obesity is considered an important risk factor for metabolic syndrome, type 2 diabetes mellitus, and cardiovascular diseases (2). Therefore, prevention and treatment of the risk factor are important. Many cellular mechanisms are involved in the development of obesity and related diseases (3). $\beta$-adrenergic signaling, which plays a critical role in metabolism, is well established to be closely related to obesity $(4,5)$. Beta3-adrenergic receptor (Adrb3) is a main agent of the $\beta$-adrenergic signaling pathway in rodent adipocytes (6). Adrb3 plays a pivotal role in the control of adipose tissue metabolism, thermogenesis $(6,7)$. Studies have shown that the expression of Adrb3 has been downregulated in white adipose tissue (WAT) of obese rodents $(8,9)$ and obese/overweight humans $(8,10,11)$. $\beta$-Arrestin (Barr) is another agent of the $\beta$-adrenergic signaling that could be complicated in obesity (12). The Barr2s constitute a small family of proteins that negatively regulate signal transduction at $G$ proteincoupled receptors, thereby playing a physiological and pathophysiological role in different cells $(13,14)$. It was recently shown that Barr2 can disturb $\beta 3$-adrenergic signaling in adipose tissue, thereby contributing to adiposity and related complications in a pathophysiologic manner (15). In this matter, the Barr2 was shown to impair the browning of WAT, defect nonshivering thermogenesis, and predispose mice to high-fat diet (HFD)-induced obesity (15). Interestingly, Pydi et al found that Barr2 expression was upregulated in subcutaneous adipose tissue of obese individuals (15). Therefore, it seems that Barr2 may be a negative regulator in obesity. In this light, finding a medical procedure that can inhibit Barr2expression may

C 2021 The Author(s); Published by Shahrekord University of Medical Sciences. This is an open-access article distributed under the terms of the Creative Commons Attribution License (http://creativecommons.org/licenses/by/4.0), which permits unrestricted use, distribution, and reproduction in any medium, provided the original work is properly cited. 
be efficient in preventing and treating obesity and related metabolic disorders.

Aerobic exercise training is well recognized as an effective medical procedure to prevent and treat obesity and related complications (16). It has been shown that aerobic training can affect many cellular signaling pathways in adipose tissue $(17,18)$. Specifically, the enhancing role of aerobic training in $\beta$-Adrenergic signaling has been reported in the WAT of mice (19). Few studies also reported that Adrb3 expression has been upregulated in adipose tissue following aerobic training in obese and nonobese rodents $(20,21)$. Based on these findings, we postulated that aerobic training could also modulate another agent of $\beta$-Adrenergic signaling such as Barr2expression in HFD-induced obesity/overweight.

Therefore, the study aimed to survey the effect of aerobic training on gene expression of Adrb3and Barr2in WAT of mice that were predisposed to overweight by HFD.

\section{Materials and Methods}

\section{Animals}

Twenty-one C57BL/6 male mice (four weeks old, body weights of $11 \pm 2 \mathrm{~g}$ ) were obtained from Experimental Study Center of Iran University of Medical Sciences and kept under controlled conditions (at $23^{\circ} \mathrm{C} \pm 2{ }^{\circ} \mathrm{C}$ with a humidity of $55 \% \pm 10 \%$ and a 12 -hour light/dark cycle). The mice were fed with standard rodent chow ad libitum with water. After a one-week acclimation, the mice were randomly assigned to three groups including 1) control (CON, n=7), 2) HFD-induced overweight (HFD-OW, $\mathrm{n}=7$ ), and 3) HFD with aerobic training (HFD-AT, $n=7$ ). The room temperature in which mice were kept was increased to $26^{\circ} \mathrm{C}$. The mice in HFD-OW group were fed with a HFD for 12 weeks. The mice in ET-AT group were subjected to aerobic training for 6 weeks along with feeding with HFD. After the experiment, mice were euthanized and blood and WAT samples were collected.

\section{High-fat diet}

The mice in HFD-OW and HFD-AT groups were fed with a HFD for 12 weeks from 5 to 17 weeks of age. The HFD contained $45 \mathrm{kcal} \%$ fat, 35\% carbohydrate, and $20 \%$ protein (total calorie $4.78 \mathrm{kcal} / \mathrm{g}$ ) (22). The mice in the control group were fed with a normal diet (15 kcal\% fat, $60 \mathrm{kcal} \%$ carbohydrates, and $20 \mathrm{kcal} \%$ protein; total calorie $3.80 \mathrm{kcal} / \mathrm{g}$ ) (23). The diets were made based on diet formula (Research Diets D12451 and D12450H) by the Research and Development Unit of Behparvar Animal Chow Company in Karaj, Iran.

\section{Aerobic-training protocol}

The mice in the ET-OW group were subjected to aerobic training for 6 weeks in addition to feeding with HFD. The 6-week training was initiated from the age of 11 weeks and terminated at the age of 17 weeks. The Aerobic training was done as a continuous running protocol on a rodent treadmill (Andisheh-Sanat, made in Iran) at 0\% inclination. This protocol which was designed based on previous studies (24-26) was performed five sessions per week, for 6 weeks and the training load was progressively increased from 15 minutes per session at $14 \mathrm{~m} / \mathrm{min}$ in the first week to 30 minutes at $20 \mathrm{~m} / \mathrm{min}$ in the last week of the protocol. The control group did not have any programmed activity.

The animals were euthanized 48 hours after the last exercise training session to avoid exercise-related acute effects.

\section{Body weight measurement}

Bodyweight was weekly measured and recorded during the experiment using electronic digital scales (ENTRIS 3202-1S S, Artorius, Germany).

\section{Tissue and blood collection}

At the end of the experiment and after fasting overnight, the mice were euthanized by intraperitoneal injection of a mixture of xylazine $(30 \mathrm{mg} / \mathrm{kg})$ and ketamine $(240$ $\mathrm{mg} / \mathrm{kg}$ ) (27). The blood samples $(0.7 \mathrm{~mL})$ were obtained from a cardiac puncture using a heparinized syringe and put immediately into siliconized disposable glass. Then, plasma was separated by centrifugation (10 minutes, $3000 \mathrm{rpm}, 4^{\circ} \mathrm{C}$ ) (Avanti J 251; Beckman, USA) and frozen $\left(-78^{\circ} \mathrm{C}\right)$ for future measurement. Inguinal subcutaneous fat pads were quickly dissected out and frozen in liquid nitrogen and stored at $-80^{\circ} \mathrm{C}$ for future measurement.

\section{Measurement of plasma parameters}

Plasma glucose was measured by glucose oxidase method (GOD-PAP) using a detection kit (Pars Azmun, Iran, 132504H917) and an autoanalyzer (Hitachi 902, Boehringer Manneheim, Germany) (28). Sensitivity and intra- and inter-assay coefficient of variations were $2 \mathrm{mg} /$ $\mathrm{dL}, 1.8 \%$ and $1.2 \%$, respectively.

Triglyceride (TG) level was determined using an enzymatic-colorimetric method by commercial kit (Pars Azmun, Iran, 117504H917) and an autoanalyzer (Hitachi 902, Boehringer Manneheim, Germany) (28). Sensitivity and intra- and inter-assay coefficient of variations were 2 $\mathrm{mg} / \mathrm{dL}, 1.7 \%$ and $1.5 \%$, respectively.

\section{Gene expression evaluation \\ RNA extraction}

Approximately $50 \mathrm{mg}$ of adipose tissue samples was homogenized in $1 \mathrm{~mL}$ of TRIzol reagent (Thermo Fisher Scientific, US). The total RNA was isolated using TRIzol in accordance with the manufacturer's instructions (Cat. No. 15596026). RNA concentration and purity were assessed (OD: 260/280) using spectrophotometers (Ultrospec 3000, Pharmacia Biotech, Sweden). The samples which had a ratio above 1.6 were selected for future procedures. cDNA synthesis

First-strand complementary DNA (cDNA) was synthesized from $1 \mu \mathrm{g}$ of RNA using Invitrogen SuperScript II Reverse Transcriptase (Thermo Fisher Scientific, USA) 
according to the manufacturer's instructions (Cat. No. 18064-014).

\section{Primers}

The primers were designed based on the methods used in previous studies (15), verified using primer-blast/NCBI and Oligo Analyzer software (1.02), and synthesized by SinaClon (Iran). The characteristics of the used primers have shown in Table 1.

\section{Real-time polymerase chain reaction}

The mRNA contents of target genes were determined by real-time polymerase chain reaction (PCR) performed using the Rotor-Gene 6000 instrument (Corbett, Australia) with SYBR Green Quantitative RT-qPCR Kit (QR0100Sigma-Aldrich, Germany) and specific primers, according to the manufacturer's instructions (Cat. No. 1907/2006). The thermal cycling profile included denaturation at $95^{\circ} \mathrm{C}$ for 10 minutes, followed by 36 cycles at $95^{\circ} \mathrm{C}$ for 10 seconds and $56^{\circ} \mathrm{C}$ for the 30 seconds according to the optimized annealing temperature of target primers.

\section{Quantification of relative gene expression}

The efficiency of PCR product and primers was determined by LinRegPCR software (version 2020.0), and the specificity of PCR products was confirmed by melting curve analysis. The relative changes in gene expression were quantified by Pfaffl method (29) (is shown below) and represented as fold change using Genex software (7.0). GAPDH served as the endogenous control.

Fold Change $=\frac{E_{\text {Tar. }}^{\Delta c p_{\text {Tar. } . \text { treat. } .}^{(\text {Con })}}}{E_{\text {Ref. } .}^{\Delta c p_{\text {Ref. }}^{(\text {Creat. } .)}}}$

Statistical analysis

Data were statistically analyzed and graphs were drawn using GraphPad Prism software version 8.0 (Irvine, CA, USA). Normal distribution of the data was verified using the Shapiro-Wilk test. Brown-Forsythe test was used to examine the homogeneity of the variances among groups. The data were reported as the mean \pm standard error of mean (SEM). Differences between groups were analyzed using one-way analysis of variance (ANOVA) followed by the Tukey's test. $P \leq 0.05$ was considered statistically significant.

Results

General characteristics

The general characteristics of the mice including variables of body weight and plasma levels of glucose and TG are shown in Table 2.

Bodyweight progressively increased over the time course of the experiment in all groups (Figure 1). After 12 weeks of the experiment, the animals in HFD-OW group displayed a significantly increased body weight compared to the control group $(P=0.001)$ (Figure 1). However, the HFD-AT group did not show a significant increase $(P=0.162)$ (Table 2). Analysis of weight gains (before and after the experiment) showed a significant increase in HFD-OW group $(63 \%, P<0.001)$ ) and HFD-AT group (40\%, $P=0.010)$ compared to the control group (Table $2)$. The HFD-AT group showed a (non-significantly) lower weight gain compared to HFD-OW group (14\%, $P=0.176$ ) (Table 2).

Both HFD-OW and HFD-AT groups displayed significantly higher fasting levels of glucose and TG compared with the control group $(P<0.05)$ (Table 2). These values in HFD-AT group were lower (but not significantly, $P>0.05$ ) when compared to HFD-OW group (Table 2).

Table 2. General characteristics of the mice in different study groups

\begin{tabular}{lccc}
\hline & $\begin{array}{c}\text { Control } \\
(\mathbf{n}=7)\end{array}$ & $\begin{array}{c}\text { HFD-OW } \\
(\mathbf{n}=7)\end{array}$ & $\begin{array}{c}\text { HFD-AT } \\
(\mathbf{n}=7)\end{array}$ \\
\hline $\begin{array}{l}\text { Body weight (g) } \\
\text { (pre) }\end{array}$ & $12.85 \pm 0.55$ & $13.07 \pm 0.68$ & $12.45 \pm 0.63$ \\
$\begin{array}{l}\text { Body weight (g) } \\
\text { (Post) }\end{array}$ & $24.14 \pm 0.87$ & $31.49 \pm 2.09^{* *}$ & $28.31 \pm 1.32$ \\
$\begin{array}{l}\text { Weight gain (g) } \\
\text { (post-pre) }\end{array}$ & $11.28 \pm 0.33$ & $18.42 \pm 1.45^{* * *}$ & $15.85 \pm 0.71^{* *}$ \\
$\begin{array}{l}\text { Glucose (mg/dL) } \\
\text { (Post) }\end{array}$ & $85.91 \pm 6.01$ & $148.0 \pm 12.33^{* *}$ & $120.45 \pm 8.45^{*}$ \\
$\begin{array}{l}\text { TG (mg/dL) } \\
\text { (Post) }\end{array}$ & $90.45 \pm 5.13$ & $145.68 \pm 9.85^{* * *}$ & $121.66 \pm 6.43^{* *}$ \\
\hline
\end{tabular}

HFD-OW: High-fat diet-induced overweight; HFD-AT: a high-fat diet with aerobic training; Pre: before experiment; Post: after the experiment; TG: triglyceride

Data are presented as mean \pm SEM. Data were analyzed using one-way ANOVA followed by Tukey's test. * $P<0.05$ ** $P<0.01$ *** $P<0.001$ compared to the control group.

Table 1. Characteristics of the used primers

\begin{tabular}{|c|c|c|c|c|c|c|}
\hline Name & Accession number & $\begin{array}{l}\text { Sequences } \\
\qquad 5^{\prime} \rightarrow 3^{\prime}\end{array}$ & $\begin{array}{l}\mathrm{Tm} \\
{ }^{\circ} \mathrm{C}\end{array}$ & $\begin{array}{c}\text { GC } \\
\%\end{array}$ & $\begin{array}{l}\text { Product length } \\
\text { (bp) }\end{array}$ & Reference \\
\hline $\begin{array}{l}\beta \text {-Arrestin1 } \\
\text { (Arrb1) }\end{array}$ & NM_177231.2 & $\begin{array}{l}\text { CCAAACCTTCCATGCTCAGT } \\
\text { TAGCCGCACAGAGTTCCTTT }\end{array}$ & $\begin{array}{l}58.08 \\
59.31\end{array}$ & $\begin{array}{l}50.00 \\
50.00\end{array}$ & 138 & (15) \\
\hline $\begin{array}{l}\beta \text {-Arrestin2 } \\
(\text { Arrb2) }\end{array}$ & NM_001271358.1 & $\begin{array}{l}\text { AAGTCGAGCCCTAACTGCAA } \\
\text { GGTGAGGGTCACGAACACTT }\end{array}$ & $\begin{array}{l}59.31 \\
59.89\end{array}$ & $\begin{array}{l}50.0 \\
55.0\end{array}$ & 144 & (15) \\
\hline $\begin{array}{l}\beta 3-\mathrm{AR} \\
(\text { Adrb3) }\end{array}$ & NM_013462.3 & $\begin{array}{l}\text { AGGCACAGGAATGCCACTCCAA } \\
\text { GCTTAGCCACAACGAACACTCG }\end{array}$ & $\begin{array}{l}64.48 \\
62.29\end{array}$ & $\begin{array}{l}54.55 \\
54.55\end{array}$ & 144 & (30) \\
\hline GAPDH & NM_001289726.1 & $\begin{array}{l}\text { AACACTGAGCATCTCССТCA } \\
\text { GTGGGTGCAGCGAACTTTAT }\end{array}$ & $\begin{array}{l}58.35 \\
58.83\end{array}$ & $\begin{array}{l}50.0 \\
50.0\end{array}$ & 113 & (31) \\
\hline
\end{tabular}

Tm: Melting Temperature; GC: guanine-cytosine content. 


\section{Relative gene expression}

Figures 2, 3, and 4 show the relative gene expression of adrb3, Barr1, and Barr2 between study groups. The Adrb3 and Barr1 gene expressions did not significantly change between groups $(P>0.05)$ (Figures 2 and 3$)$. However, the gene expression of $\beta$-Arrestin 2 was higher in HFD-OW group than in the control group $(P=0.001)$ and was lower in HFD-AT group when compared with OW-HFD group (Figure 4).

\section{Discussion}

The findings of this study include the following: First, HFD, which had a fattener effect, caused an increase in Barr2 gene expression. However, the HFD did not significantly change the expression of Barr1 and Adrb3

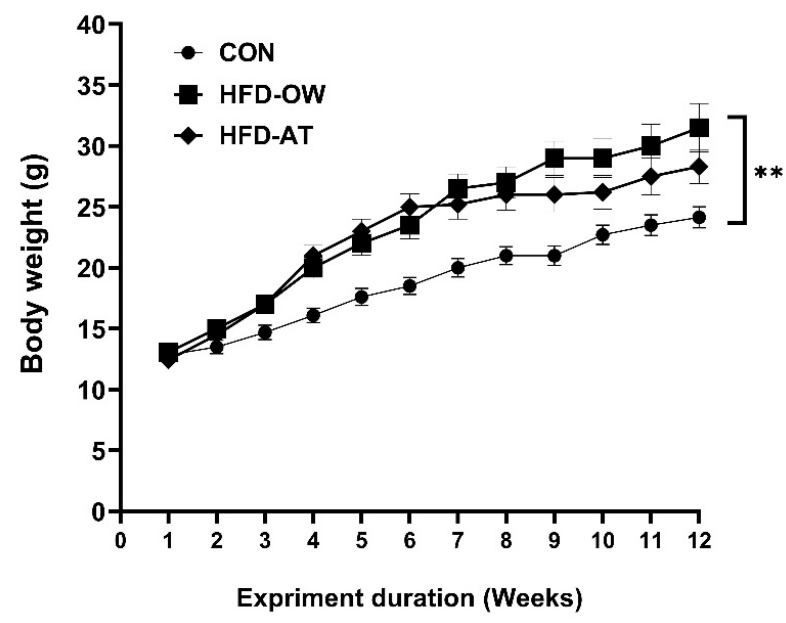

Figure 1. Bodyweight during the experiment period.

CON: Control ( $n=7)$; HFD-OW: High-fat diet-induced overweight; HFD-AT: a high-fat diet with aerobic training. Data are presented as mean \pm SEM. Data were analyzed by one-way ANOVA followed by Tukey's test. ${ }^{* *} P<0.01$ compared to the control group.

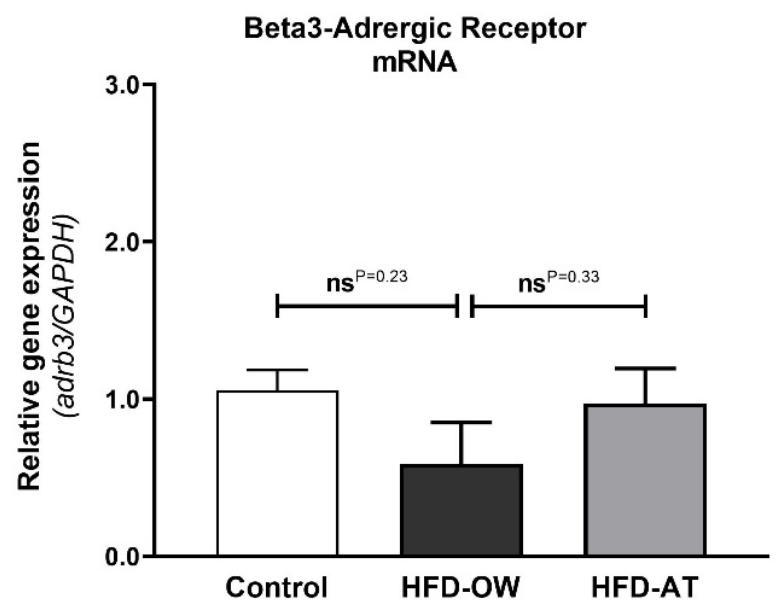

Figure 2. Relative gene expression of Beta3 adrenergic receptor (Adrb3) in the study groups.

HFD-OW: High-fat diet-induced overweight; HFD-AT: high-fat diet with aerobic training. Data are presented as mean \pm SEM. Data were analyzed by one-way ANOVA followed by Tukey's test.

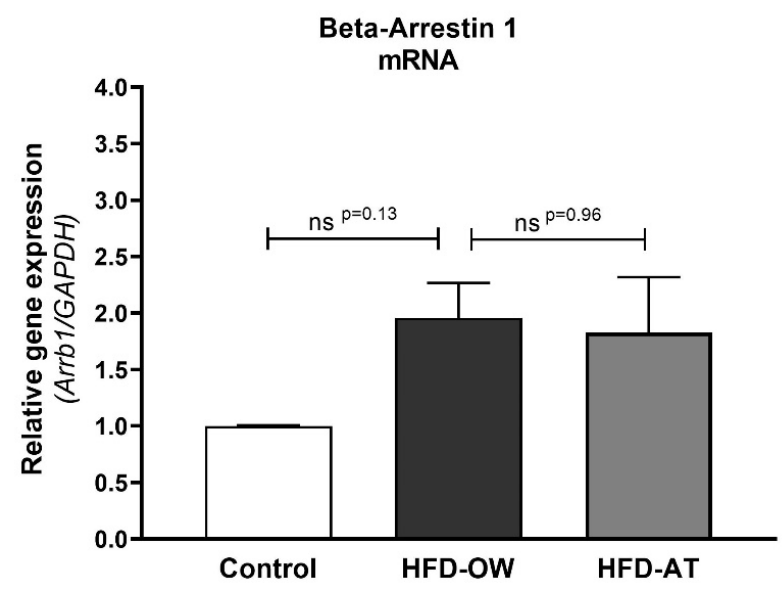

Figure 3. Relative gene expression of beta arrestin 1 (Arrb1) in the study groups.

HFD-OW: High-fat diet-induced overweight; HFD-AT: high-fat diet with aerobic training. Data are presented as mean \pm SEM. Data were analyzed by one-way ANOVA followed by Tukey's test.

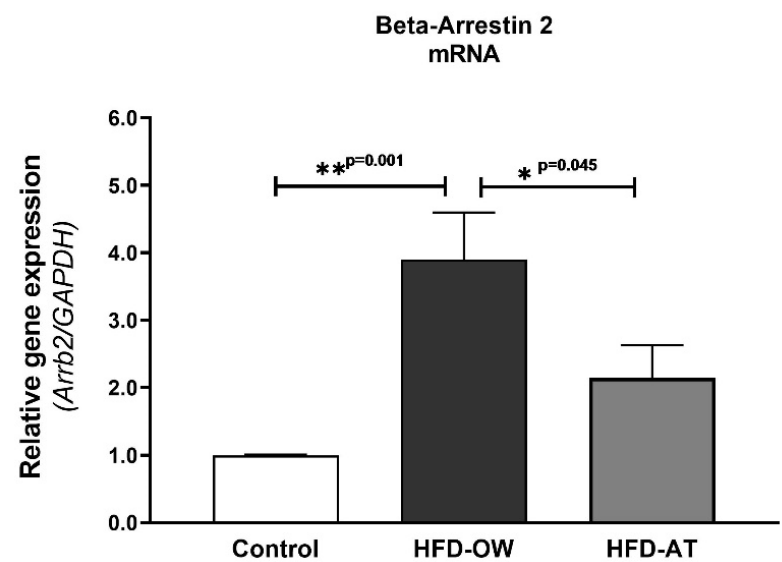

Figure 4. Relative gene expression of beta arrestin 2 (Arrb2) in the study groups.

HFD-OW: High-fat diet-induced overweight; HFD-AT: high fat diet with aerobic training. Data are presented as mean \pm SEM. Data were analyzed by one-way ANOVA followed by Tukey's test.

genes. Second, the aerobic training significantly prevented the increase of Barr2 induced by the HFD. Nevertheless, the training did not significantly change the expression of Barr1 and Adrb3. Data showed that the post-experiment weight of the HFD-OW group was increased by $30 \%$ as compared to the control group. This suggested that the HFD had a fattener effect. Besides, they suggested that the HFD-OW group likely became obese/overweight. This suggestion was based on a review study reporting that the HFD-induced weight increase of $10 \%$ to $25 \%$ compared to the control group has been considered as moderate obesity (32). We cautiously hypothesized that the group was overweight. Further, the post-experiment weight of the HFD-AT group was $17 \%$ higher (but not significantly) than the control group. This might indirectly imply that the aerobic training prevented HFD-induced overweight. Notably, the Lee index was not used to estimate the degree of obesity in this study, because the index was examined 
on rats and mostly applied to rats rather than mice $(32,33)$. An important finding of this study was that the Barr2 gene expression was increased in HFD-OW group as compared to the control group. This was consistent with a previous study on humans showing that Barr2 gene expression was higher in subcutaneous WAT of the obese individuals as compared to age-matched non-obese ones (15). $\beta$-Arrs can suppress $\beta$-adrenergic signaling pathway by trafficking (internalization) mechanism (14). Therefore, these results raised the possibility that the $\beta$-adrenergic signaling may be impaired in adipose tissue as a result of HFD-induced overweight. However, in this study, we did not find a significant change in Barr1 expression in HFD-OW group as compared to the control group. This finding suggested that the transcription of the subtypes of Barr genes may be stimulated by different manners.

In contrast to the hypothesis, data did not show a significant reduction in Adrb3 gene expression in HFDOW group compared to the control group. However, some previous studies have reported a downregulation in Adrb3 gene expression in WAT of obese rodents $(8,9)$. This inconsistency might be due to two factors including the composition of HFD and the temperature of the environment in which mice were kept. In this study, HFD consisted of $45 \%$ fat, whereas, in the previous works, the amount of fat was $60 \%$. In this study, mice were kept at $26^{\circ} \mathrm{C}$, whereas, in previous studies, mice were kept at $22^{\circ} \mathrm{C}$. Recent investigations have shown that the standard temperature (i.e., $22^{\circ} \mathrm{C}$ ) can chronically induce light/cold stress in mice and may thus stimulate thermogenic mechanisms such as an expression of Adrb3 and uncoupling protein 1 in WAT of mice $(35,36)$. Overall, it was speculated that the HFD-induced overweight may impair the $\beta 3$-adrenergic signaling by upregulating Barr2 gene expression. Sine $\beta 3$-adrenergic signaling is essential for inducing catabolism (i.e., lipolysis and FFA oxidation) and thermogenesis $(6,37)$, it was thought that the deficiency of $\beta 3$-adrenergic signaling may be linked to dysregulation of fat oxidation and energy expenditure, probably developing obesity and its metabolic disorders.

Additionally, no significant change was observed in Adrb3 expression in HFD-AT group as compared to both HFD-OW and control groups. This finding was similar to that in a previous work by Rodrigues et al who reported that endurance training for eight weeks did not change in Adrb3 gene expression in WAT of mice (38). However, there are a few studies that reported an increase in Adrb3 expression following endurance training in WAT of rats that had a normal (21) and HFD (20). The reason(s) for the discrepancy is not clear. Nevertheless, this is perhaps related to rodent species. In the studies reporting the increase of Adrb3, subjects were rats, whereas, in the current study and the one conducted by Rodrigues et al, reporting no change in the expression of Adrb3, subjects were mice. Based on a few studies, Adrb3 expression may be differently affected in different rodent species. However, this needs further studies.
The main result of this study was that Barr2 gene expression was lower in HFD-AT group than in HFD-OW group. This result indicated that aerobic training could prevent the increase of Barr2 gene expression that was induced by HFD. Further, exercise was previously reported to acutely reduce the expression of Barr2 in WAT of mice (39). Considering that Barr 2 can desensitize $\beta$-adrenergic signaling in adipocytes, this finding suggested that aerobic training may prevent the desensitization of $\beta$-adrenergic signaling by downregulating Barr2.

\section{Conclusion}

The gene expression of Adrb3 and Barr1 was not changed either by HFD or aerobic training in WAT of mice. However, the aerobic training could inhibit the upregulation of Barr2 gene expression that was induced by HFD. This indicated that aerobic training may prevent $\beta$-adrenergic-signaling deficiency by modifying the Barr2 expression. Further, it would be suggested that the partially preventive effect of aerobic training on the development of obesity and obesity-related diseases may be mediated by modulating the Barr2 expression.

\section{Conflict of Interests}

The authors declare no competing interests.

\section{Ethical Approval}

All experimental procedures were conducted under international guidelines for the care and use of laboratory animals and were approved by the Ethics Committee at the University of Ayatollah Alozma Boroujerdi (Approval ID: ABRU.AC.IR/15664-96.42) on January 12, 2018.

\section{Authors' Contributions}

SD designed and performed the experiments, MD contributed to laboratory measurements, and data analysis, YF contributes to performing the experiment protocol and collection of data. All authors approved the final version manuscript.

\section{Funding/Support}

The present study was financially supported by the University of Ayatollah Alozma Boroujerdi (15664-214256).

\section{Acknowledgments}

This article was derived from a research study (15664-214256) conducted at the University of Ayatollah Alozma Boroujerdi. We thank Dr. Fateme Jalali for helping with laboratory measurements.

\section{References}

1. Chooi YC, Ding C, Magkos F. The epidemiology of obesity. Metabolism. 2019;92:6-10. doi: 10.1016/j. metabol.2018.09.005.

2. Ludwig DS. The glycemic index: physiological mechanisms relating to obesity, diabetes, and cardiovascular disease. JAMA. 2002;287(18):2414-23. doi: 10.1001/ jama.287.18.2414.

3. Armani A, Berry A, Cirulli F, Caprio M. Molecular mechanisms underlying metabolic syndrome: the expanding role of the adipocyte. FASEB J. 2017;31(10):4240- 
55. doi: 10.1096/fj.201601125RRR.

4. Masuo K, Lambert GW. Relationships of adrenoceptor polymorphisms with obesity. J Obes. 2011;2011:609485. doi: 10.1155/2011/609485.

5. Finlin BS, Memetimin H, Zhu B, Confides AL, Vekaria HJ, El Khouli RH, et al. The $\beta 3$-adrenergic receptor agonist mirabegron improves glucose homeostasis in obese humans. J Clin Invest. 2020;130(5):2319-31. doi: 10.1172/ jci134892.

6. Collins S. $\beta$-Adrenoceptor signaling networks in adipocytes for recruiting stored fat and energy expenditure. Front Endocrinol (Lausanne). 2011;2:102. doi: 10.3389/ fendo.2011.00102.

7. Cero C, Lea HJ, Zhu KY, and Cypess AM. 2020-P: ß3Adrenergic receptors regulate lipolysis and thermogenesis in human brown/beige adipocytes. Diabetes. 2020;69(Suppl 1). doi: $10.2337 / \mathrm{db} 20-2020-\mathrm{P}$.

8. Komai AM, Musovic S, Peris E, Alrifaiy A, El Hachmane MF, Johansson $M$, et al. White adipocyte adiponectin exocytosis is stimulated via $\beta 3$-adrenergic signaling and activation of Epac1: catecholamine resistance in obesity and type 2 diabetes. Diabetes. 2016;65(11):3301-13. doi: 10.2337/db15-1597.

9. Collins S, Daniel KW, Rohlfs EM. Depressed expression of adipocyte beta-adrenergic receptors is a common feature of congenital and diet-induced obesity in rodents. Int J Obes Relat Metab Disord. 1999;23(7):669-77. doi: 10.1038/ sj.ijo.0800894.

10. Kurylowicz A, Jonas M, Lisik W, Jonas M, Wicik ZA, Wierzbicki $Z$, et al. Obesity is associated with a decrease in expression but not with the hypermethylation of thermogenesis-related genes in adipose tissues. J Transl Med. 2015;13:31. doi: 10.1186/s12967-015-0395-2.

11. Cao WY, Liu Z, Guo F, Yu J, Li H, Yin X. Adipocyte ADRB3 down-regulated in Chinese overweight individuals adipocyte ADRB3 in overweight. Obes Facts. 2018;11(6):524-33. doi: 10.1159/000495116.

12. Pydi SP, Jain S, Barella LF, Zhu L, Sakamoto W, Meister J, et al. $\beta$-arrestin-1 suppresses myogenic reprogramming of brown fat to maintain euglycemia. Sci Adv. 2020;6(23):eaba1733. doi: 10.1126/sciadv.aba1733.

13. van Gastel J, Hendrickx JO, Leysen H, Santos-Otte P, Luttrell LM, Martin B, et al. $\beta$-Arrestin based receptor signaling paradigms: potential therapeutic targets for complex agerelated disorders. Front Pharmacol. 2018;9:1369. doi: 10.3389/fphar.2018.01369.

14. Smith JS, Rajagopal S. The $\beta$-arrestins: multifunctional regulators of $\mathrm{G}$ protein-coupled receptors. J Biol Chem. 2016;291(17):8969-77. doi: 10.1074/jbc.R115.713313.

15. Pydi SP, Jain S, Tung W, Cui Y, Zhu L, Sakamoto W, et al. Adipocyte $\beta$-arrestin-2 is essential for maintaining whole body glucose and energy homeostasis. Nat Commun. 2019;10(1):2936. doi: 10.1038/s41467-019-11003-4.

16. O'Gorman DJ, Krook A. Exercise and the treatment of diabetes and obesity. Endocrinol Metab Clin North Am. 2008;37(4):887-903. doi: 10.1016/j.ecl.2008.07.006.

17. Tsiloulis T, Watt MJ. Exercise and the regulation of adipose tissue metabolism. Prog Mol Biol Transl Sci. 2015;135:175201. doi: 10.1016/bs.pmbts.2015.06.016.

18. Thompson D, Karpe F, Lafontan M, Frayn K. Physical activity and exercise in the regulation of human adipose tissue physiology. Physiol Rev. 2012;92(1):157-91. doi: 10.1152/physrev.00012.2011.

19. Snook LA, Trottier SK, Worndl EA, Bombardier E, Tupling AR, MacPherson REK. Prior endurance training enhances beta-adrenergic signaling in epidydimal adipose from mice fed a high-fat diet. Obesity (Silver Spring). 2017;25(10):1699-706. doi: 10.1002/oby.21933.

20. Aldiss P, Lewis JE, Lupini I, Bloor I, Chavoshinejad R, Boocock DJ, et al. Exercise training in obese rats does not induce browning at thermoneutrality and induces a musclelike signature in brown adipose tissue. Front Endocrinol (Lausanne). 2020;11:97. doi: 10.3389/fendo.2020.00097.

21. Stephenson EJ, Lessard SJ, Rivas DA, Watt MJ, Yaspelkis BB 3rd, Koch LG, et al. Exercise training enhances white adipose tissue metabolism in rats selectively bred for low- or high-endurance running capacity. Am J Physiol Endocrinol Metab. 2013;305(3):E429-38. doi: 10.1152/ ajpendo.00544.2012.

22. Yang Y, Smith DL Jr, Keating KD, Allison DB, Nagy TR. Variations in body weight, food intake and body composition after long-term high-fat diet feeding in C57BL/6J mice. Obesity (Silver Spring). 2014;22(10):214755. doi: 10.1002/oby.20811.

23. Benoit B, Plaisancié P, Awada M, Géloën A, Estienne M, Capel F, et al. High-fat diet action on adiposity, inflammation, and insulin sensitivity depends on the control low-fat diet. Nutr Res. 2013;33(11):952-60. doi: 10.1016/j.nutres.2013.07.017.

24. Teixeira-Coelho F, Fonseca CG, Barbosa NHS, Vaz FF, Cordeiro LMS, Coimbra CC, et al. Effects of manipulating the duration and intensity of aerobic training sessions on the physical performance of rats. PLoS One. 2017;12(8):e0183763. doi: 10.1371/journal.pone.0183763.

25. Høydal MA, Wisløff U, Kemi OJ, Ellingsen O. Running speed and maximal oxygen uptake in rats and mice: practical implications for exercise training. Eur J Cardiovasc Prev Rehabil. 2007;14(6):753-60. doi: 10.1097/ HJR.0b013e3281eacef1.

26. Wang Y, Wisloff U, Kemi OJ. Animal models in the study of exercise-induced cardiac hypertrophy. Physiol Res. 2010;59(5):633-44. doi: 10.33549/physiolres.931928.

27. Miranda CS, Silva-Veiga F, Martins FF, Rachid TL, Mandarim-De-Lacerda CA, Souza-Mello V. PPAR- $\alpha$ activation counters brown adipose tissue whitening: a comparative study between high-fat- and high-fructosefed mice. Nutrition. 2020;78:110791. doi: 10.1016/j. nut.2020.110791.

28. Daneshyar S, Gharakhanlou R, Nikooie R, Forutan Y. The effect of high-fat diet and streptozotocin-induced diabetes and endurance training on plasma levels of calcitonin gene-related peptide and lactate in rats. Can J Diabetes. 2014;38(6):461-5. doi: 10.1016/j.jcjd.2014.03.001.

29. Pfaffl MW. A new mathematical model for relative quantification in real-time RT-PCR. Nucleic Acids Res. 2001;29(9):e45. doi: 10.1093/nar/29.9.e45.

30. Lehmann M, Nguemo F, Wagh V, Pfannkuche K, Hescheler J, Reppel M. Evidence for a critical role of catecholamines for cardiomyocyte lineage commitment in murine embryonic stem cells. PLoS One. 2013;8(8):e70913. doi: 10.1371/journal.pone.0070913.

31. Parousis A, Carter HN, Tran C, Erlich AT, Mesbah Moosavi ZS, Pauly M, et al. Contractile activity attenuates autophagy suppression and reverses mitochondrial defects in skeletal 
muscle cells. Autophagy. 2018;14(11):1886-97. doi: 10.1080/15548627.2018.1491488.

32. Hariri N, Thibault L. High-fat diet-induced obesity in animal models. Nutr Res Rev. 2010;23(2):270-99. doi: $10.1017 / \mathrm{s} 0954422410000168$.

33. Lee MO. Determination of the surface area of the white rat with its application to the expression of metabolic results. Am J Physiol. 1929;89(1):24-33. doi: 10.1152/ ajplegacy.1929.89.1.24.

34. Fischer AW, Cannon B, Nedergaard J. Optimal housing temperatures for mice to mimic the thermal environment of humans: an experimental study. Mol Metab. 2018;7:16170. doi: 10.1016/j.molmet.2017.10.009.

35. Bastías-Pérez M, Zagmutt $S$, Soler-Vázquez MC, Serra D, Mera P, Herrero L. Impact of adaptive thermogenesis in mice on the treatment of obesity. Cells. 2020;9(2):316. doi: 10.3390/cells9020316.

36. David JM, Chatziioannou AF, Taschereau R, Wang H, Stout
DB. The hidden cost of housing practices: using noninvasive imaging to quantify the metabolic demands of chronic cold stress of laboratory mice. Comp Med. 2013;63(5):386-91.

37. Collins S, Surwit RS. The beta-adrenergic receptors and the control of adipose tissue metabolism and thermogenesis. Recent Prog Horm Res. 2001;56:309-28. doi: 10.1210/ rp.56.1.309.

38. Rodrigues AC, Leal TF, Costa A, de Jesus Silva F, Soares LL, Brum PC, et al. Effects of aerobic exercise on the inflammatory cytokine profile and expression of lipolytic and thermogenic genes in $\beta(1)$-AR(-/-) mice adipose tissue. Life Sci. 2019;221:224-32. doi: 10.1016/j.lfs.2019.02.031.

39. Ogasawara J, Sanpei M, Rahman N, Sakurai T, Kizaki T, Hitomi $\mathrm{Y}$, et al. Beta-adrenergic receptor trafficking by exercise in rat adipocytes: roles of G-protein-coupled receptor kinase-2, beta-arrestin-2, and the ubiquitinproteasome pathway. FASEB J. 2006;20(2):350-2. doi: 10.1096/fj.05-4688fje. 